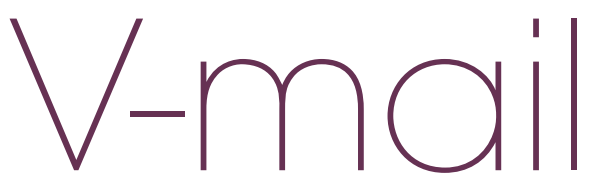

Send your views to

vitaleditorial@nature.com

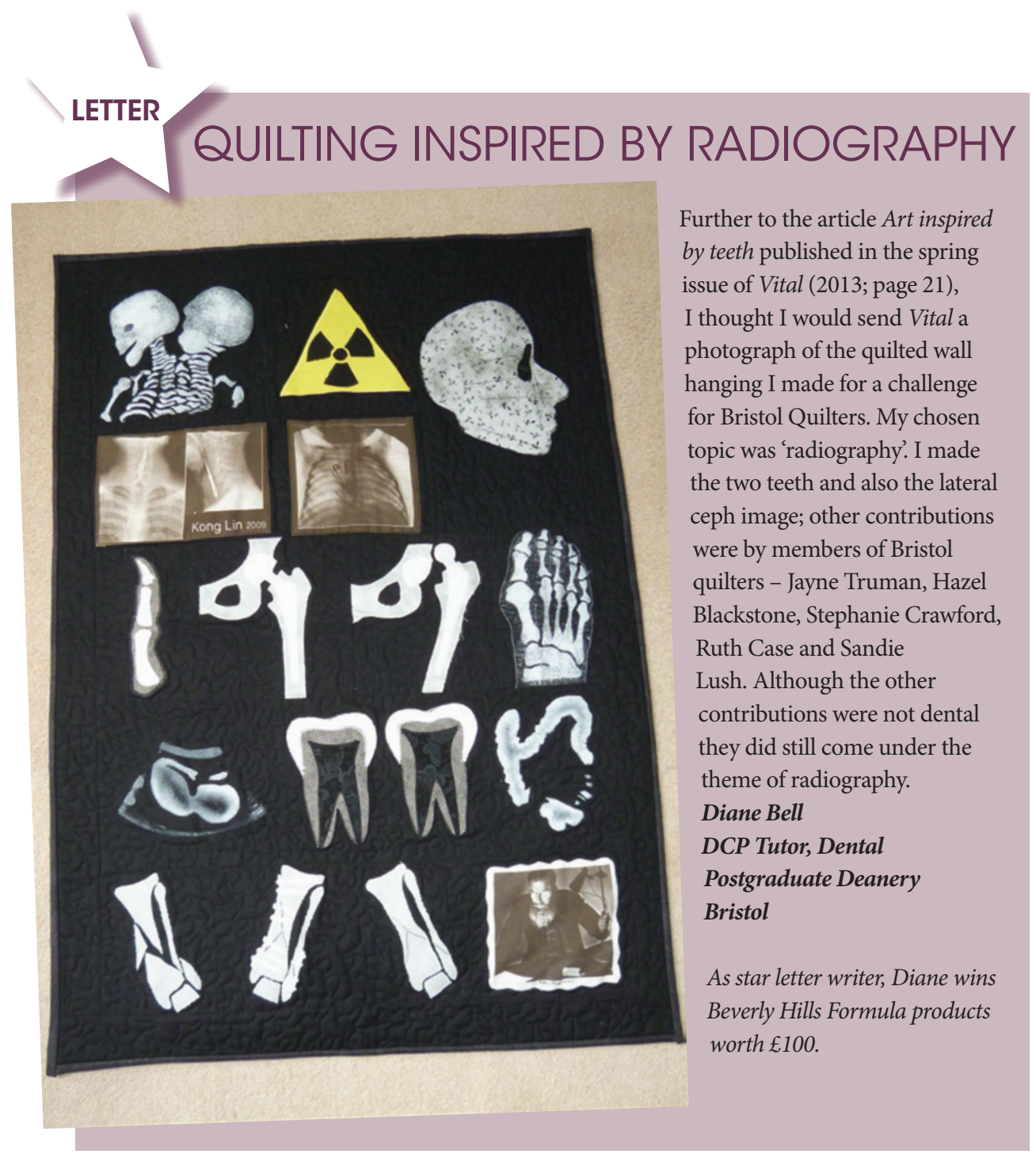

\title{
SNAIL MAIL RULES
}

I just want to say thank you for making it possible to take part in Vital CPD through the post. I'm very old fashioned and hate computers. I do not have one at home and only use one at work because I have to! Thanks again for making my life a little easier.

\section{Hall RDN}

Southwell

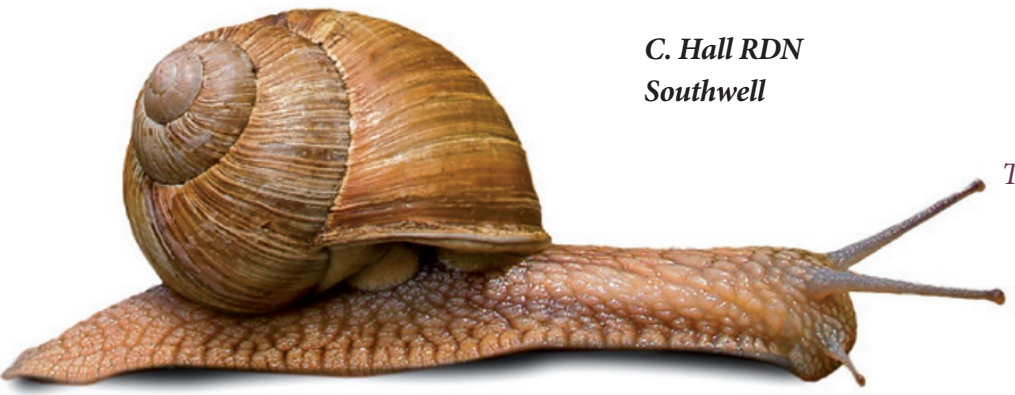

Turn to pages 49-52 to find out more about taking part in Vital CPD.

\section{IN FOR A}

\section{CPD SHOCK}

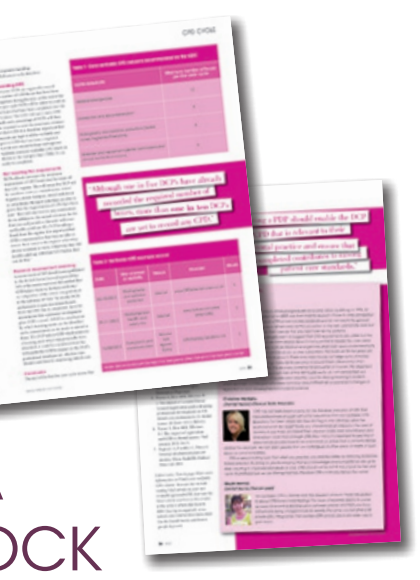

I particularly enjoyed Nicky Gough's article Do you have no hours of CPD? (Vital winter 2012 pages 34-36); this article provide all DCPs with some timely advice as to what is needed before the end of the CPD cycle (for lots of us) in July 2013. Maybe it is time for practice owners and managers to be checking portfolios prior to the end of cycle date, to ensure that we are not looking for new staff in August 2013!

It was perhaps more interesting to read the thoughts of other DCPs in the Reader Panel section. One panel member seemed to suggest that they have so much verifiable CPD that they don't record general CPD, which in my opinion appears to be missing the point.

Whilst obviously having a proactive attitude to completing their $\mathrm{CPD}$ requirements, this panel member seems to be advocating a system where achieving certification is more important than the actual learning. This attitude perpetuates the myth that the CPD system is no more than an exercise in income generation for courses in order to collect CPD points.

Some of the most effective learning I receive is from on-the-job vocational learning and not from those training courses which result in a certificate. I have often heard complaints from staff that some of the verifiable learning has been ineffective at best and completely worthless at worst.

Perhaps it is the right time to look at whether all CPD could be verifiable. Practice/team meetings are already vCPD (subject to meeting GDC criteria) and it is not too difficult to expand this along the range of general CPD activities.

Having assisted two of my own dentists with submitting CPD to the GDC I am of the opinion that those who have no CPD but who are under the illusion that they won't be asked to show proof are in for a shock later this year.

\section{Michael Pilling}

RDN, Cert Ed, Member of the Institute for Learning 